\title{
AVALIAÇÃO DOS IMPACTOS DE USO PÚBLICO NA TRILHA ECOLÓGICA DA PRAIA DO PERIGOSO - PARQUE NATURAL DE GRUMARI, RJ
}

\author{
Adriano Oliveira da Silva ${ }^{1}$ \\ Adão Osdayan Cândido de Castroº
}

\section{RESUMO}

Os impactos negativos decorrentes do uso público em Unidades de Conservação (UCs) são cada vez mais latentes no Brasil. Apesar de possuir avançada legislação relacionada às UCs, o país ainda encontra dificuldades operacionais de fiscalização e de estudos de monitoramento. Neste sentido, este trabalho tem como principal objetivo de avaliar os impactos de uso público na trilha ecológica da Praia do Perigoso, localizada no Parque Municipal de Grumari, Zona Oeste da cidade do Rio de Janeiro. Buscou-se identificar, através da análise da microtopografia do solo, os principais geoindicadores de erosão, em virtude do fluxo de visitantes somado aos fatores naturais. Destacam-se, portanto, a presença em diversos setores, de sulcos de erosão, ravinamentos prolongados e profundos, o que pode dificultar e restringir o uso da trilha.

Palavras-chave: Unidades de conservação; Impactos de uso público; Geoindicadores de erosão.

\begin{abstract}
The negative impacts of public use in Conservation Units (CUs) are increasingly latent in Brazil. Although it has advanced legislation related to CUs, the country still faces operational difficulties in the supervision and monitoring studies. Thus, the main aim of this work is to evaluate the impacts of public use of the ecological track on the Perigoso Beach, located on Municipal Park of Grumari, Rio de Janeiro's West Zone. In order to meet the proposed objective, we sought to verify, through the analysis of soil's microtopography, the main geoindicators of erosion, by virtue of the stream of visitors in association to the natural factors. They stand out, therefore, the presence in various sectors of erosion grooves, long and deep ravines, which can hinder and restrict the use of the track.
\end{abstract}

Keywords: Conservation Units; Impacts of Public Use; Geoindicators of erosion.

\section{INTRODUÇÃO}

O uso público nas Unidades de Conservação (UCs) é uma atividade que vem crescendo no Brasil e no mundo, devido à busca das populações urbanas por áreas onde a natureza ainda se mantem preservada. As UCs são de grande importância para a manutenção dos recursos naturais existentes no planeta. No Brasil, o Sistema Nacional de Unidades de Conservação da Natureza (SNUC) foi instituído pela Lei no 9.985 de 18 de julho de 2000 que

\footnotetext{
${ }^{1}$ Licenciado em Geografia pela Universidade Federal Fluminense. E-mail: adrianos@id.uff.br

${ }^{2}$ Geógrafo, Mestrando em Geografia pela Universidade Federal Fluminense. E-mail: adaocastro@id.uff.br
} 
estabelece critérios e normas para a criação, implantação e gestão das UCs. Esta lei foi um grande avanço na definição das classificações e dos objetivos de manejo destas áreas. $\mathrm{O}$ SNUC divide as UCs em duas categorias: as de Proteção Integral e as de Uso Sustentável, a primeira é subdividida em cinco categorias e a segunda em sete categorias ${ }^{4}$.

Em algumas UCs são desenvolvidas atividades de uso público, como: recreação, práticas educativas, esportivas e de lazer que são permitidas com a finalidade de promover a interação com o meio ambiente e, com isso, propiciar a conservação dos recursos naturais. Contudo, se as atividades não forem planejadas respeitando as vulnerabilidades e as potencialidades da área visitada, pode vir a comprometer o estado de conservação das mesmas. Segundo Vallejo (2002, p. 57):

As Unidades de Conservação, na atualidade, representam uma das formas de (re) ordenamento territorial e ambiental, visto que estes espaços têm como princípio reduzir as perdas da biodiversidade face à degradação ambiental imposta pela sociedade.

É pertinente a compreensão de que as UCs devem ultrapassar sua concepção como espaços de preservação de ecossistemas e de seus recursos naturais. Estas devem ser consideradas como espaços de relações socioambientais historicamente configurados e dinamicamente movidos por tensões e conflitos sociais, integrando-as ao desenvolvimento regional, fortalecendo as interações sociais e a participação cidadã.

O termo uso público, é definido como o processo de visitação das áreas protegidas, podendo se manifestar como atividades educativas, de lazer, esportivas, recreativas, científicas e de interpretação ambiental, que proporcionam ao visitante a oportunidade de conhecer, entender e valorizar os recursos naturais e culturais existentes (MINISTÉRIO DO MEIO AMBIENTE, 2005). Também segundo Magro (1999, apud PIMENTEL, 2013) “[...] pode ser definido como o usufruto gozado pelo público usuário, que realiza diferentes atividades como a recreação, o turismo, a educação ambiental, a pesquisa e até mesmo, ritos religiosos".

A busca das populações por um maior contato com as áreas silvestres, a fim de escapar do estresse urbano causado pelas grandes aglomerações nas cidades, pode causar impactos negativos às áreas de visitação, como: compactação do solo em trilhas, ravinamentos, erosão, lixo, depredações, entre outros. Segundo Vallejo (2013), impactos negativos são modificações em propriedades biológicas, químicas e físicas do meio ambiente e que podem ser causadas por agentes naturais, humanos ou pela combinação de ambos.

\footnotetext{
${ }^{4}$ Unidades de Proteção Integral visa preservar a natureza, sendo admitido apenas o uso indireto dos seus recursos naturais, com exceção dos casos previstos nesta Lei, com cinco categorias: Estação Ecológica (ESEC) Reserva Biológica (REBIO), Parque Nacional (PARNA), Monumento Natural (MN), Refúgio de Vida Silvestre (REVIS); Unidades de Uso Sustentável que estabelece a conciliação entre a conservação da natureza com o uso sustentável de parcela dos seus recursos naturais, com sete categorias: Área de Proteção Ambiental (APA), Área de Relevante Interesse Ecológico (ARIE), Floresta Nacional (FLONA), Reserva Extrativista (RESEX), Reserva de Fauna (REFAU), Reserva de Desenvolvimento Sustentável (RDS) e Reserva Particular do Patrimônio Natural (RPPN).
} 
O uso público pode trazer também benefícios à área de visitação, mas desde que a haja um bom programa de planejamento, como destaca Santos (2010):

Um Programa de Uso Público deve levar em consideração coletas de dados, avaliações relacionadas com visitantes, participação de comunitários na organização e desenvolvimento das atividades, o desenvolvimento de estruturas adequadas, zoneamento, estratégias de receitas e fiscalização, e ênfase na qualidade interpretativa e programas de educação ambiental, bem como ter uma clara compreensão dos objetivos de gestão da unidade inserida.

Lecner (2009 apud SANTOS, 2010) complementa que "Um bom planejamento para uso público começa com um claro entendimento dos objetivos da área e como o uso público e as pesquisas são relatadas". Takahashi (2004 apud SANTOS, 2010) complementa que "[...] o programa de uso público é um dos componentes do plano de manejo, devendo estar inserido no planejamento total da unidade para garantir maior eficiência na administração e manejo da área”.

Nesta perspectiva, a elaboração de um bom plano de manejo aliado ao estudo do uso público nas áreas de visitação se tornam essenciais para que as UCs possam ser liberadas para a visitação, mas infelizmente nem sempre é o que acontece, visto que algumas UCs recebem um grande número de visitantes antes mesmo da confecção do seu plano de manejo ${ }^{5}$. Santos (2010) ressalta que o plano de manejo:

[...] é o documento técnico mais importante da área, que estabelece o zoneamento, o diagnóstico e o manejo dos recursos naturais, além de normalizar as pesquisas, a utilização e visitação. A lei do SNUC, em seu artigo 27, determinou que todas as unidades de conservação devem dispor de um plano de manejo e que sem este documento, é apenas permitido atividades de conservação e fiscalização.

A partir do entendimento das potencialidades e limitações das UCs, torna-se importante a elaboração de estudos que analisem os impactos negativos decorrentes do uso público, principalmente em trilhas ecológicas. Neste sentido, este trabalho tem como principal objetivo de avaliar os impactos de uso público na trilha ecológica da Praia do Perigoso, localizada no Parque Municipal de Grumari, Zona Oeste da cidade do Rio de Janeiro. O uso público na trilha vem causando latentes impactos negativos decorrentes do pisoteio dos frequentadores, somado aos fatores naturais (Chuva, Vegetação, Geologia, etc.).

A trilha da Praia do Perigoso está inserida numa Unidade de Conservação, o Parque Natural de Grumari, uma área de proteção ambiental (APA), com 966,32 ha de extensão,

\footnotetext{
${ }^{5} \mathrm{O}$ plano de manejo pode ser definido como "um ciclo contínuo de consulta e tomada de decisão com base no entendi mento das questões ambientais, socioeconômicas, históricas e culturais que caracterizam uma Unidade de Conservação e a região onde esta se insere". A criação de espaços territoriais especialmente protegidos, dentre estes as UCs, é considerada uma das melhores estratégias para a conservação da biodiversidade (KINKER, 2002 apud REZENDE et al, 2013).
} 
criada através da lei municipal no 944 de 30 de dezembro de 1986. Está localizada no extremo sul do maciço da Pedra Branca, na Serra de Guaratiba, no bairro de Barra de Guaratiba, RJ (Figura 01).

Nesta região, são desenvolvidas diversas atividades ligadas às práticas de uso público, como: recreação (banho de mar, caminhada), práticas esportivas entre outras atividades. E a trilha da Praia do Perigoso é principal acesso para se chegar aos pontos onde são praticadas as atividades citadas, sofrendo com o pisoteio dos caminhantes.

Ressalta-se que este trabalho é experimental e as medições realizadas não podem ser ainda comparadas. Pretende-se avaliar o comportamento da trilha por um período de um ano para, assim, mensurar o potencial de erosão causado pelo uso público.

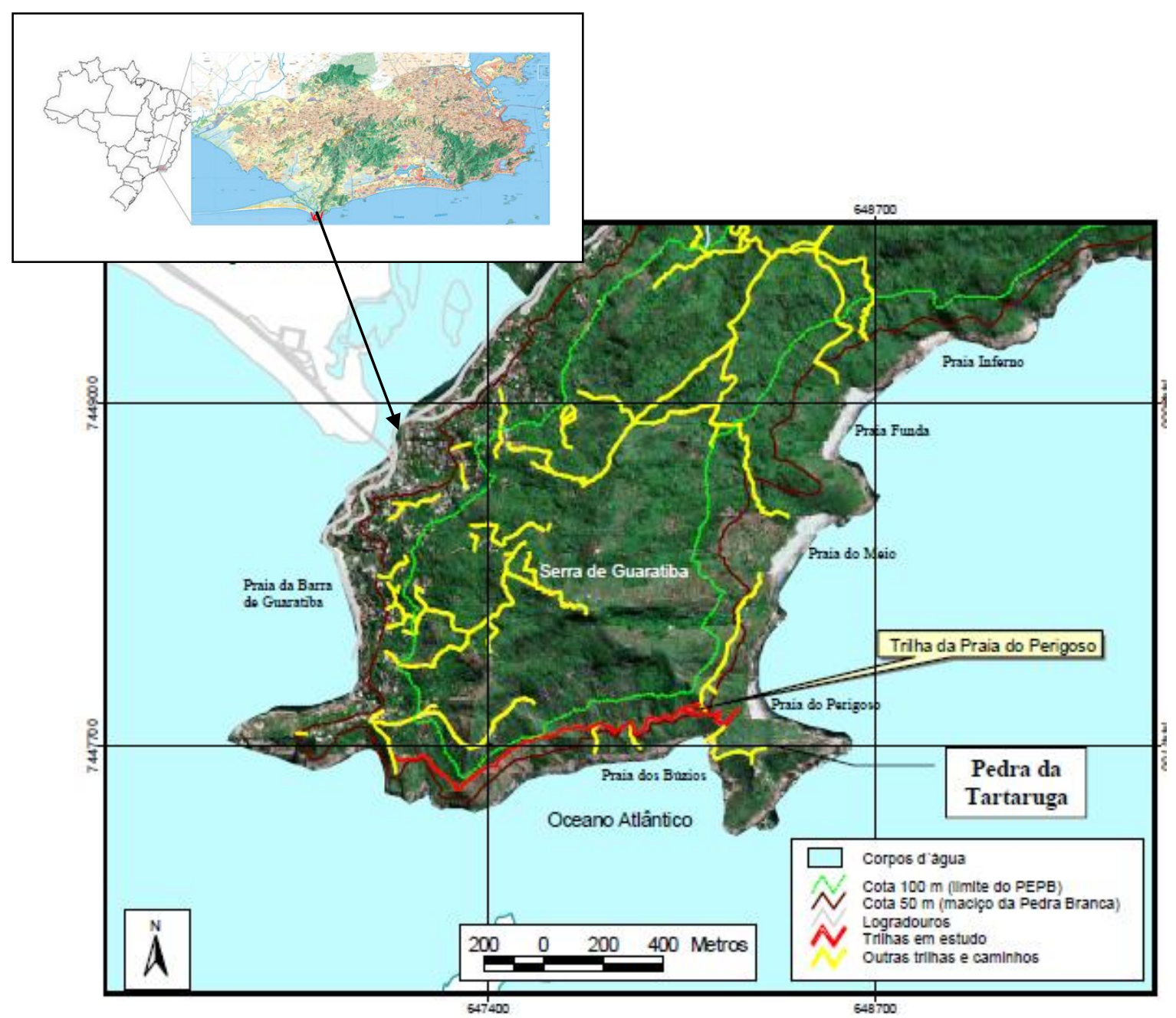

Figura 01: Mapa de Localização da Trilha da Praia do Perigoso. Fonte: Castilho, 2006.

\section{MATERIAIS E MÉTODOS}

\section{Referencial Teórico}


Para Gaudie (1995) o volume total de erosão que ocorre numa encosta é resultado de processos geomorfológicos que incluem a ação das gotas de chuva e o escoamento superficial difuso e concentrado, que, por sua vez, dependem de uma série de fatores que englobam a erosividade da chuva, a erodibilidade do solo, as características das encostas, a cobertura vegetal e o uso e manejo do solo.

Nesta perspectiva, os estudos das causas de erosão hídrica em trilhas ecológicas, bem como os impactos associados ao desgaste do solo, devem levar em consideração alguns aspectos condicionantes para que aconteça ativação dos processos erosivos. Nomeadamente, as taxas de precipitação, nível de declividade, composição do solo e presença vegetacional.

A precipitação é o fator mais significante, pois é condicionante substancial para ativação dos processos de erosão hídrica em trilhas. Os efeitos provenientes da chuva são diversos, vão desde a desagregação das partículas de solo, escoamento (difuso e laminar), além de condicionar outros aspectos inerentes à sua função, como o transporte e deposição dos sedimentos erodidos.

A declividade é outro aspecto condicionante para ativação dos processos de erosão hídrica, e neste sentido a trilha da Praia do Perigoso apresenta valores significativos de inclinação $\left(15 \mathrm{a} 45^{\circ}\right)$. Neste caso, pode-se entender que quanto maior o declive e o comprimento do sulco ou ravina, maiores serão as atuações dos processos erosivos. Por exemplo, num terreno com maior declive, as águas provenientes da precipitação escorrem com maior velocidade, arrastando mais sedimentos.

Na literatura, por outro lado, há discordâncias a sobre o potencial da declividade na ativação desses processos. Segundo Morgan (1989 e 2005), fatores como a declividade podem ser condicionantes na ação de processos erosivos em trilhas ecológicas, porém não há necessariamente uma correlação positiva à medida que a declividade aumenta, porque a literatura relacionada a esse fator mostra, através de vários exemplos, que em trilhas muito íngremes a erosão pode diminuir devido ao decréscimo de material disponível.

Desta forma, a declividade pode ser uma das causas da instabilidade, porém deve-se analisar este fator correlacionado-o com outros aspectos, como por exemplo a estrutrura do solo, a capacidade de infiltração e o nível de compactação. Nos dois pontos de análise, percebeu-se que essa correlação foi reponsável pelo processo intenso de desgaste do solo, porém não foi possível a realização de medição para detectar o grau de inclinação nos pontos amostrais

A vegetação é outro fator de importância na atuação dos processos erosivos no solo. Portanto, em solos com muita vegetação a erosão tende a ser menor, visto que a velocidade da água da chuva diminui por conta da barreira provocada pelo extrato vegetacional e não cai diretamente no solo, logo será menor a quantidade de sedimentos que serão desintegrados e transportados. Além disso, diminui-se a velocidade do escoamento da água na superfície, pois se a vegetação é uma barreira para a água que cai sobre o solo, é também para aquela que desliza sobre. No caso da área de estudo em questão, apresenta-se com pouca vegetação no 
ponto 01 (Figura 03), por isso há uma maior atuação dos agentes erosivos, essencialmente da chuva.

O solo, último fator analisado, é considerado o resultado da adaptação das rochas às condições do meio em que se encontram expostas (ex: precipitação; temperatura;). Alguns fatores externos ao solo contribuem para sua taxa erosividade, ou seja, a menor ou maior capacidade de dado processo provocar erosão. Por outro lado, deve-se considerar também, a erodibilidade do solo, que é a susceptibilidade do solo sofrer erosão, ou seja, a capacidade de sua resistência aos fatores externos.

\section{Métodos operacionais}

Como condutor dos estudos, utilizou-se como base a metodologia adotada por Ferreira (1996), que serviu de suporte para as técnicas e equipamentos de campo, bem como para todo processo analítico.

Para a construção da "ponte de erosão", equipamento utilizado para medir a microtopografia do solo, foram necessários os seguintes materiais: estacas de madeira de 50 centímetros (úteis para o nivelamento), sarrafos de 3 metros (ponte de erosão), vareta de ferro de 1 metro (vareta de medição). A ponte possui 116 furos (pontos de análise), distribuídos numa equivalência de 2,5 centímetros.

Para a instalação da "ponte de erosão" foi necessário fincar as duas estacas nas bordas da seção transversal escolhida, que possui 3 metros. Logo depois, utilizou-se o nível de madeira para nivelar. Os valores de cada ponto foram retirados com o auxílio de uma trena de medição, como pode ser observado na Figura 05.

Os valores foram inseridos numa ficha de campo e lançados em planilhas do software Microsoft Excel 2007 para a elaboração dos gráficos de microtopografia. Ressalta-se, que os gráficos que serão analisados ilustram apenas o estágio atual de erosão da trilha, mas pode ser importante ferramenta de análise dos impactos causados pelo uso público em UCs.

\section{RESULTADOS}

\section{Caracterização geral da trilha}

A trilha possui cerca de $1,5 \mathrm{~km}$, apresenta padrão linear, onde ida e volta são feitas pelo mesmo caminho. A mesma inicia-se na estrada da Bica, atravessando as bacias hidrográficas de Guaratiba e Guaratiba leste, acessando as praias do Perigoso e dos Búzios. (COSTA, 2006).

O percurso oferece algumas dificuldades de acesso, com alguns obstáculos, como: trechos íngremes e rochas no leito da trilha, onde a declividade do terreno - com forte gradiente, devido aos costões rochosos pode variar entre $15^{\circ}$ a $25^{\circ}$ na baixa-meia encosta, chegando a $45^{\circ}$ na alta-encosta. A geologia apresenta afloramentos de rocha gnáissica ácida e básica da série inferior e superior, associados a solos podzólico vermelho e amarelo raso, com textura médio-argilosa (COSTA, 2006). 
A vegetação encontra-se em estagio inicial de regeneração, devido ao reflorestamento feito pela prefeitura do município do Rio de Janeiro em parceria com a comunidade local. Há alguns pontos na trilha onde a reflorestamento está em estágio avançado, produzindo sombra, como no ponto 01 de análise. Por outro lado, o ponto 02 sofre com a falta de vegetação, produzindo uma alta incidência de luz, aumentando o impacto da chuva sobre o solo.

\section{Análise dos perfis de microtopografia - Perfil 01}

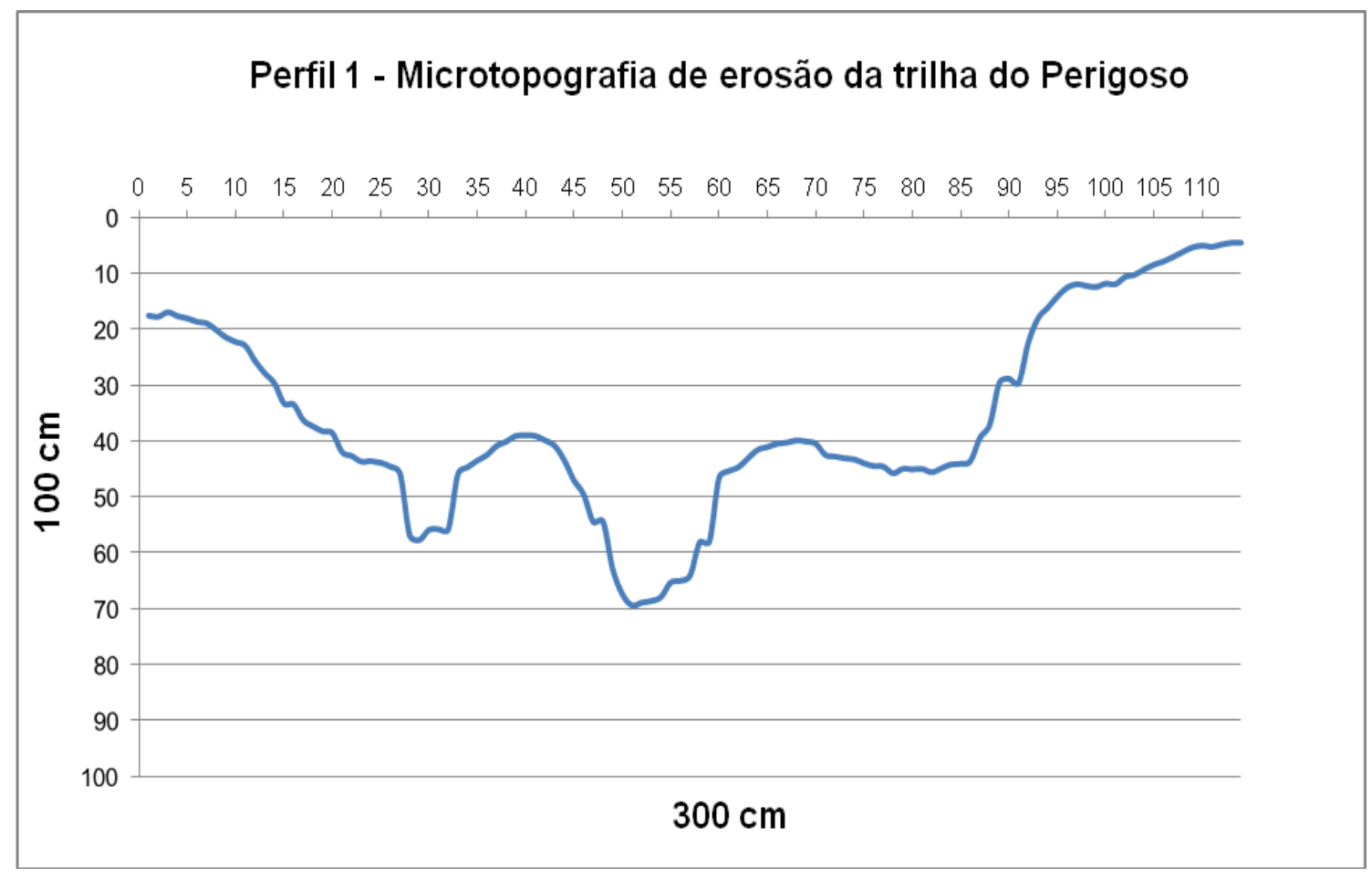

Figura 02: Gráfico de microtopografia do solo da trilha da Praia do Perigoso - Perfil 01.

O perfil 01 está localizado no setor inicial da trilha, alinhado ao eixo de declividade. Em virtude desta condicionante, o perfil torna-se principal catalisador do fluxo superficial, e por seguinte, da drenagem superficial do solo, apresentando microformas erosivas de ravinas e sulcos de erosão. Percebem-se dois sulcos principais com relativa profundidade.

O primeiro com espessura entre 20 a 30 centímetros e 20 centímetros de profundidade, com formato côncavo, subdivido em dois outros pequenos sulcos. No segundo, observa-se maior espessura, entre 50 a 60 centímetros e aprofundamento com formato côncavo variando entre 30 a 35 centímetros de profundidade. Observa-se também, entre os pontos 60 e 85 a formação de outro sulco de erosão, provocado pelo setor do perfil que recebe maior parte do movimento de pisoteio e arrastamento provocado pelos frequentadores da trilha.

Estes movimentos somados a falta de serrapilheira geram a compactação e desagregação da camada superficial do solo, o que pode contribuir para o aparecimento de 
novos sulcos de erosão, diminuindo ainda mais sua erodibilidade, tornando o ambiente susceptível à erosão hídrica. Somando a isto, a presença rarefeita de vegetação expõe o solo aos efeitos de erosividade da chuva, o que acentua o aporte de sedimentos retirados.

Observou-se nesta parte da trilha grande dificuldade por parte dos freqüentadores e a grande declividade somada às irregularidades do solo pode provocar acidentes. Este setor deve receber técnicas de manejo o quanto antes, é preciso estabelecer um novo padrão de escoamento da água, descentralizando o fluxo da trilha.

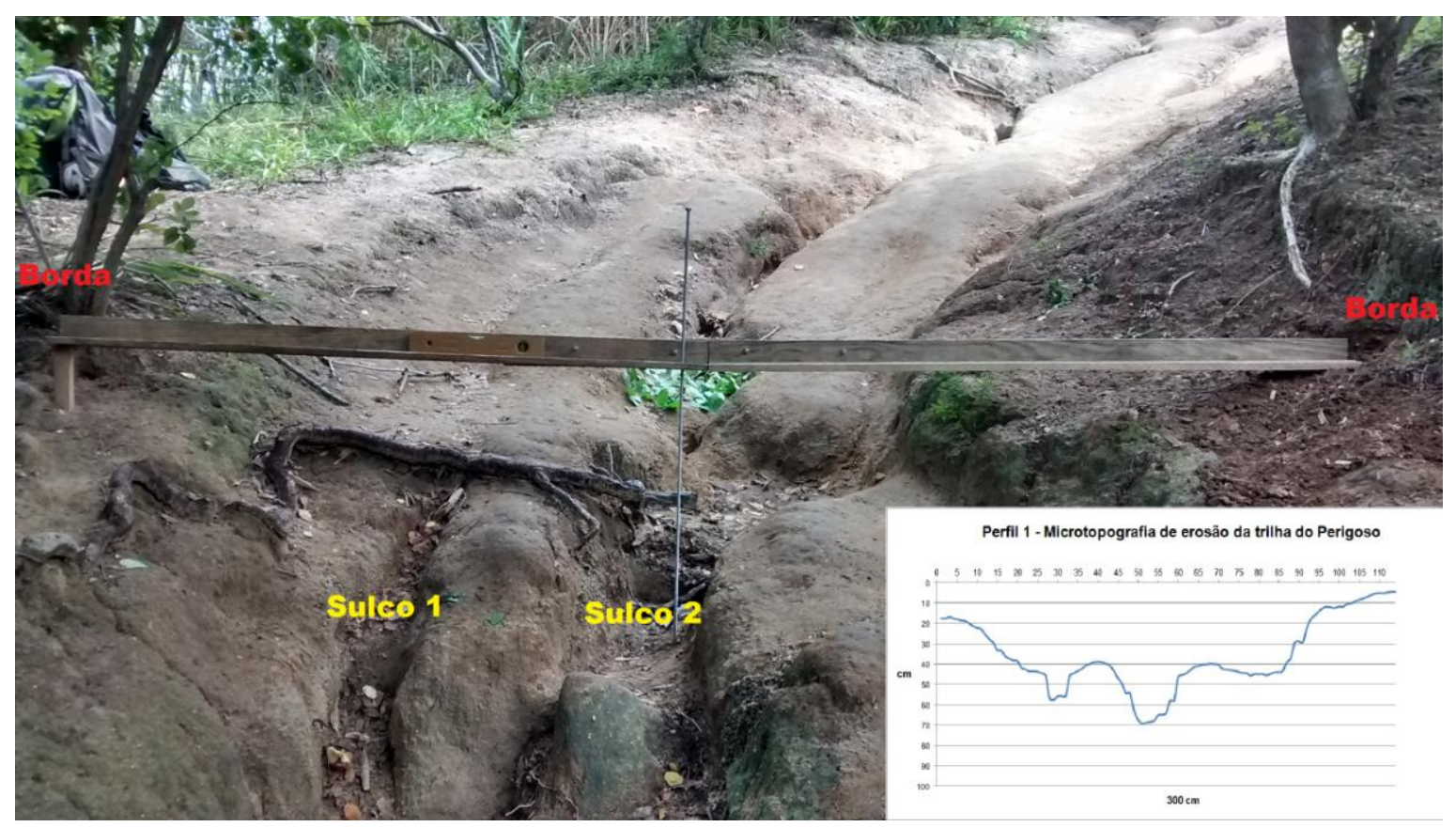

Figura 03: Sulcos de erosão no perfil de análise 01 .

\section{Análise dos perfis de microtopografia - Perfil 02}

O perfil 02 está localizado no final da trilha do Perigoso. Apresenta alta declividade, obedece ao eixo direcional da trilha, que o torna o principal canal de escoamento do fluxo superficial, como também da drenagem solo. São observados dois grandes sulcos de erosão, o primeiro na borda esquerda da trilha com $60 \mathrm{~cm}$ de largura e $25 \mathrm{~cm}$ de profundidade. $\mathrm{O}$ segundo, na borda direita, apresenta uma largura de $50 \mathrm{~cm}$ e uma profundidade acentuada de $40 \mathrm{~cm}$.

É perceptível através da análise do gráfico, dois pontos de ruptura tendencial do gráfico, os mesmos são reflexos de raízes expostas na trilha, que pode ser outro indicador de erosão (Figura 04). A presença de vegetação é mais rarefeita do que o primeiro perfil, com predomínio de espécies arbustivas sem grandes copas. Isso acarreta o impacto direto da chuva sobre o solo exposto (Figura 05). 
Comparado ao primeiro trecho da trilha, este setor apresenta alto grau de dificuldade em virtude da declividade e dos sulcos de erosão presentes na trilha. Neste trecho é visível à presença de rochas expostas, matacões desagregados e pequenos blocos de rochas, o que evidencia o intenso processo de erosão.

Foi perceptível a grande dificuldade de acesso neste setor por parte dos visitantes, o trecho apresenta sérios riscos de acidentes. Devem-se adotar medidas emergenciais de manejo através da interdição e mudança do trajeto.

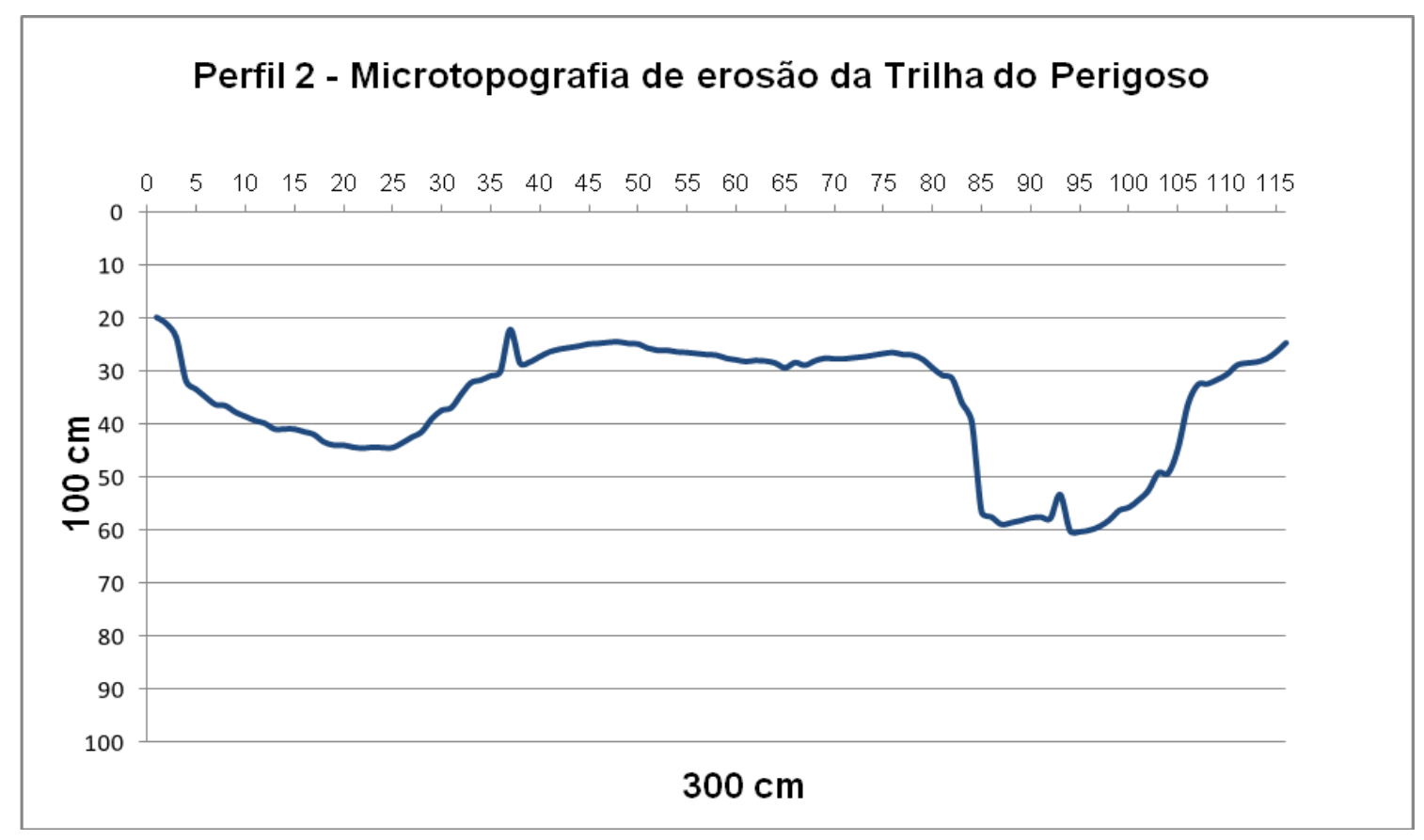

Figura 04: Gráfico de microtopografia do solo da trilha da Praia do Perigoso - Perfil 02. 


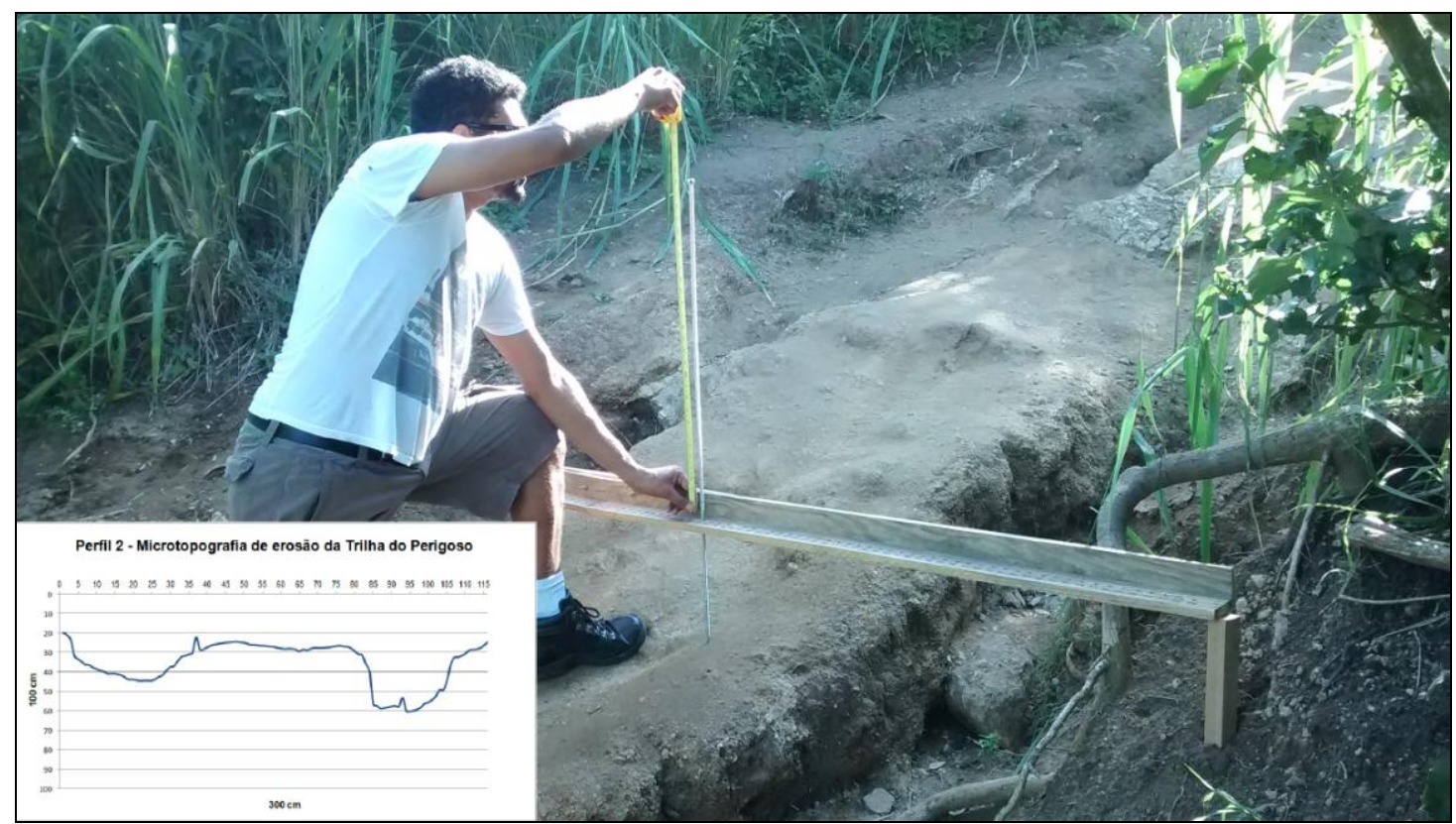

Figura 05: Sulcos de erosão no perfil de análise 02. Fonte: Autores

\section{CONCLUSÕES}

A trilha ecológica da Praia do Perigoso vem recebendo cada vez um maior número de visitantes, atraídos principalmente pelo acesso às praias ainda não urbanizadas na cidade do Rio de Janeiro. A beleza cênica, a tranquilidade e a possibilidade de prática de diversas atividades esportivas e de lazer fazem do local, um ponto de atração para moradores de diversas regiões da cidade e até do exterior.

Este grande número de visitantes somado aos fatores geoambientais (solo, chuva, vegetação) acarretam uma série de impactos negativos no uso da trilha. Foi perceptível em diversos pontos, geoindicadores de erosão como sulcos profundos e até ravinamentos.

A técnica de microtopografia do solo demonstrou-se muito eficiente para análise das formas erosivas nos perfis de amostra. Associados a esta técnica, a análise detalhada do número de visitantes, índices pluviométricos, estudos do solo e geologia da região, poderão contribuir para mensurar o potencial erosivo da trilha, e pode colaborar para a elaboração de um plano manejo. 
Devem-se tomar medidas emergenciais por parte do poder público, através de técnicas de manejo de uso da trilha. Os pontos mais críticos deverão ser interditados e desviados para novos trechos, como também será necessário o mapeamento de novos segmentos que levem em consideração a geomorfologia e declividade da região. Se estas medidas não forem tomadas o quanto antes, poderá provocar acidentes e comprometer o acesso de visitantes.

\section{BIBLIOGRAFIA}

BRASIL. LEI No 9.985, de 18 de julho de 2000 - Institui o Sistema Nacional de Unidades de Conservação da Natureza (SNUC). Brasília: IBAMA, Diretoria de Ecossistemas, 2002. $35 \mathrm{p}$.

COSTA, V. C. da. Proposta de manejo e planejamento ambiental de trilhas ecoturísticas: um estudo no maciço da Pedra Branca - Município do Rio de Janeiro - RJ. 2006, Tese Centro de Ciências Matemáticas e da Natureza - Instituto de Geociências - Programa de PósGraduação em Geografia - Universidade Federal do Rio de Janeiro.

FERREIRA, C. G.- Erosão hídrica em solos florestais. Estudo em povoamentos de Pinuspinaster e Eucalyptus globulus em Macieira de Alcôba. Águeda, Revista da Faculdade de Letras, Geografia, I Série, vol. XII/XIII, Porto, p. 145-244. 1996/97

GOUDIE, A. The Changing Earth - Rates of Geomorphological Processes. Oxford, Oxford, Blackwell Publishers, 302p. 1995

GOUDIE, A; VILES, H. The Earth Transformed - An Introduction to Human Impacts on the Environment. Oxford, Blackwell Publishers, 276 p. 1997

GUERRA, A. J. T. (Org.) Geomorfologia urbana. Rio de Janeiro, Bertrand Brasil, 14p. 2011

INSTITUTO IGUAÇU - Disponível em <

http://www.instiguacuambiental.org.br/Parques/grumari.htm $>$ - Acesso em 18/05/2015

MINISTÉRIO DO MEIO AMBIENTE. Diagnóstico da visitação em parques nacionais e Estaduais. Brasília: Ministério do Meio Ambiente. Secretaria de Biodiversidade e Florestas, 2005.

MORGAN, R. P.C. Soil Erosion and Conservation. England, Longman Group, 298 p. 1986

p. 2005

. Soil Erosion and Conservation. England, Blackwell Publishers, $3^{\text {a }}$ edição, 304

PIMENTEL D. de S. Parcerias para a gestão do uso público em parques. Anais - Uso Público em Unidades de Conservação,n. 1,v. 1, 2013 Niterói - RJ. Disponível em < http://www.uff.br/usopublico >. Acesso em 15/01/2015.

QUEIROZ, E. D. de. Contribuições da educação ambiental crítica para o uso público sustentável em unidades de conservação, 2013 - Anais - Uso Público em Unidades de 
Conservação, n.1, v.1, 2013 Niterói - RJ. Disponível em < http://www.uff.br/usopublico $>$. Acesso em 15/01/2015.

RODRIGUES, C. G. O. O uso do público nos parques nacionais: a relação entre as esferas pública e privada na apropriação da biodiversidade. Brasília, 2009. 358 f. Tese (Doutorado em Desenvolvimento Sustentável) - Centro de Desenvolvimento Sustentável da Universidade de Brasília, Brasília, 2009. Disponível em: <

http://www.nuredam.kinghost.net/files/publicacoes/teses/tese_Camila_Rodrigues.pdf $>$ Acesso em 06/06/2014

SANTOS, A.M - O ecoturismo, uso público e o parque Nacional do Iguaçu, Fórum Ambiental da Alta Paulista. Periódico Eletrônico, volume VI - ANAP - Associação Amigos da Natureza da Alta Paulista. 2010. Disponível em < http://amigosdanatureza.org.br/publicacoes/index.php/forum_ambiental/issue/view/7 > Acesso em 06/01/2015.

VALLEJO, L.R - Uso público em áreas protegidas: atores, impactos, diretrizes de planejamento e gestão, 2013 - Anais - Uso Público em Unidades de Conservação, n.1, v.1, 2013 Niterói - RJ. Disponível em < http://www.uff.br/usopublico > Acesso em 04/06/2014.

VALLEJO, L. R. Unidades de Conservação: uma discussão teórica à luz dos conceitos de território e políticas Públicas. In: GEOgraphia, Niterói, v. 4, n. 8, p. 57-78, 2002. 